\section{The commonality of subjective organization in free recall*}

\author{
S. I. SHAPIRO \\ University of Hawaii, Honolulu, Hawaii 96822
}

\begin{abstract}
Measures of bidirectional commonality and bidirectional ratio of commonality are presented to assess the extent of inter-S agreement of subjective organization in free recall. The results of an experiment employing the commonality measure indicate that commonality increases across trials and is positively correlated with the amount of recall. However, the amount of commonality is relatively low. The low amounts of commonality were confirmed further by analyzing the data of three additional and independent studies of free recall.
\end{abstract}

While the existence of subjective organization in free recall is now well documented (e.g., Tulving, 1968), relatively little attention has been devoted to analyzing the extent to which such organizational strategies are common among Ss. A further question of interest is whether or not the commonality of organizational strategies substantially increases with trials. If such a convergence in strategies does occur, it may be possible to develop a useful classification system of the kinds of subjective organizational strategies employed in free recall and their frequencies of usage with various kinds of materials and $S$ populations.

The most common measure of subjective organization currently in use is that of observed minus expected intertrial repetitions, (O-E)ITRs (Bousfield \& Bousfield, 1966). While this measure was originated to determine the amount of intra-S subjective organization for adjacent trials, the measure can be easily restructured to assess the amount of inter-S subjective organization for any given trial. To obtain the present commonality measure, the number of bidirectional ${ }^{1}$ intratrial repetitions are tabulated for all possible pairs of Ss on the trial. Similarly, the corresponding chance expected values for each pair of Ss is subtracted from their respective numbers of observed intratrial repetitions. The commonality score for a given $S$ then consists of the mean observed minus expected intratrial repetitions between himself and the other Ss on the trial. The expected (E) values were generated by employing Gorfein, Blair, \& Rowland's (1968) formula (originally used for intertrial organization): $E=[2 C(C-1)] / h k$, where $C$ is the number

*This research was supported by a grant from the University of Hawaii Research Council. Jerold A. Bell assisted in collecting the data and Judith $M$. Nishizaki assisted in their analysis. The author is grateful for the computer time generously made available by the University of Hawaii Statistical and Computing Center. of items in common to two $\mathrm{Ss}$ on a given trial, $h$ is the number of items recalled by one $\mathrm{S}$, and $\mathrm{k}$ is the number of items recalled by a second $\mathrm{S}$. Ratio scores of commonality were also computed based on Gorfein, Blair, \& O’Neill's (1969) formula for ratio scores of bidirectional intertrial organization. The formula ${ }^{2}$ employed in the present study was [(bidirectional observed intratrial repetitions $) /(C-1)]-2 \mathrm{C} / \mathrm{hk}$.

Bidirectional commonality and commonality ratio scores, rather than unidirectional scores, were computed in the present study, since there are no a priori reasons why the members of an organizational unit need always be in the identical serial order. Recent empirical evidence (Anderson \& Watts, 1969) also suggests that a bidirectional measure of organization is more sensitive than a unidirectional measure. There is also ample evidence of bidirectional organization in associative clustering (e.g., Shapiro \& Palermo, 1967). Where it is desired to obtain unidirectional measures of commonality and ratio of commonality scores, it is only necessary to delete multiplying by 2 in the formulae described above.

\section{METHOD}

A list was composed of 20 words selected from a larger group which were minimally interassociated in terms of free association norms (List X employed by Quaintance \& Shapiro, 1970). Of the 380 possible interitem associations, there were only $2(1.6 \%$ and $0.2 \%)$. The Thorndike-Lorge (1944, G count) word frequencies of 13 of the words were AA or $A$, and the remaining words ranged from $8-40$ occurrences per million. Twelve randomized orders of the 20 words were prepared such that no word appeared more than once in the same serial position and no word was succeeded or followed by the same word more than once. The 12 orders were employed for 12 trials, consisting of alternating presentation-recall periods. Approximately equal numbers of Ss were started randomly on three different orders in the series of 12 orders. The words were presented on slides by means of a Kodak Carousel slide projector and an associated timing device for $1 \mathrm{sec}$ each, with a $1-\mathrm{sec}$ interval between exposures when the slide changed. Recall was written, and each of the 12 recall periods was $80 \mathrm{sec}$. The Ss were given free recall instructions that stressed that the number of words recalled was important and not the order of their recall.

The Ss were 24 male and female native English-speaking volunteers from introductory psychology classes at the University of Hawaii. The Ss were tested in groups of 2-5. No $S$ had participated in any prior free-recall experiment, and all but a few were naive to any verbal-learning experiment.

\section{RESULTS AND DISCUSSION}

Intrusions and duplicate responses were omitted in calculating all measures; both kinds of responses were minimal and were not further analyzed. Mean recall and

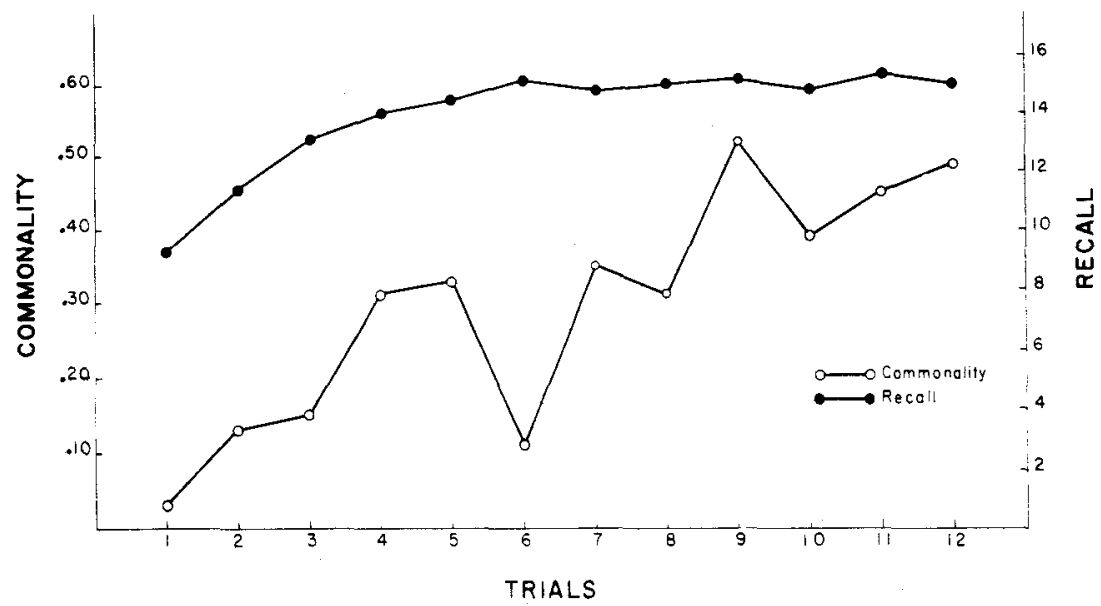

Fig. 1. Mean commonality and recall scores per trial. Recall scores are plotted relative to the right ordinate, and commonality scores are plotted relative to the left ordinate. 
Table 1

Correlations Between Recall, Commonality, and Intertrial Organization

\begin{tabular}{lccc}
\hline & $\begin{array}{c}\text { Recall- } \\
\text { Commonality }\end{array}$ & $\begin{array}{c}\text { Recall- } \\
\text { Intertrial } \\
\text { Organization }\end{array}$ & $\begin{array}{c}\text { Commonality- } \\
\text { Intertrial } \\
\text { Organization }\end{array}$ \\
\hline Produce-Moment & $+0.79^{*}$ & $+0.64^{*}$ & $+0.56^{*}$ \\
Partial & $+0.68^{*}$ & +0.39 & +0.11 \\
\hline
\end{tabular}

$* p<.01$

commonality scores for each trial are plotted in Fig. 1. The amount of commonality clearly increases as Ss progress through trials. However, in terms of the commonality ratio scores computed, there is little evidence of any systematic increase across trials, and the highest mean score for any trial was only .05 . Thus, the ratio scores indicate little in the way of a relative increase in commonality, although recall is near ceiling. For both commonality measures, all but one $S$ had positive scores. However, the mean commonality scores per trial were not significantly larger than zero, $t(23)=1.81$ (two-tailed). A similar analysis of the ratio of commonality scores resulted in $\mathbf{t}(23)<1$.

To investigate further the generality of these findings, commonality and commonality-ratio scores were also calculated for the data of three independent free-recall studies, in which different word lists, presentation intervals, and list lengths were employed (Shapiro, 1970; Shapiro \& Bell, 1970b; Shapiro \& Ponce, 1970). The results were all very similar to the present study in magnitude and trends across trials.

Intertrial subjective organization was also calculated for successive trial pairs using the formula for bidirectional (O-E)ITR provided by Gorfein, Blair, \& Rowland (1968). The (O-E)ITR scores systematically increased from 0.15 on Trial Pair $1-2$ to 1.98 on Trial Pair 11-12 (mean across all trial pairs $=1.10$ ). Table 1 presents Pearson product-moment correlations between mean overall recall, commonality, and intertrial organization scores. The three measures are all significantly positively correlated with one another. However, the table also indicates that in terms of partial correlations only recall and commonality scores remain significantly correlated. Thus, it appears that the primary association among the three measures is between recall and common organizational units and that the association between intertrial organization and recall may be partially dependent on a subset of organizational units, i.e., those units employed in common by Ss. It must be remembered, however, that commonality scores are based on between-S comparisons on a single trial, and intertrial organization scores are based on within-S comparisons across adjacent trial pairs.

The basis of the present measure of commonality is not substantially different from a measure employed by Tulving (1962) in which data were pooled on each trial into a recall matrix for all $S s$ and inter-S agreement in subjective organization was then computed. Tulving, too, found a consistent increase in commonality across trials, but, again, the absolute increases were relatively slight. Furthermore, the inter-S subjective organization scores presented by Tulving are not compared with chance-expected values. Carterette \& Coleman (1963) have also called attention to the problem of possible artifactual increases in commonality across trials when chance-expected recall sequences merely due to increasing recall are not taken into account. In addition to accounting for chance-expected values in the present commonality measures described, their sensitivity to bidirectional organization is also an advantage.

In addition to Tulving's (1962) study, Bousfield and his associates have employed Kendall's coefficient of concordance to assess commonality by comparing mean recall emission orders among Ss, but these analyses have been confined to criterion trials late in learning (Abramczyk \& Bousfield, 1967; Abramczyk \& Bousfield, 1969; Bousfield \& Abramczyk, 1966; Bousfield, Puff, \& Cowan, 1964). With the exception of lists consisting of nonsense syllables varying in meaningfulness (Abramczyk \& Bousfield, 1969), significant amounts of commonality have been found, although the correlation coefficients have been consistently relatively low.

The minimal amount of commonality found in the present study and others cited, although it is significantly associated with the amount of recall, is not surprising. Intertrial organization itself has typically been relatively low also, although consistently correlated with the amount of recall (e.g., Shapiro \& Bell, 1970a). It is precisely the low amounts of organization-relative to the memory burden they are assumed to support-that has led some investigators to question the adequacy of the crganizational hypothesis to account for the free recall of unrelated lists of words (Carterette \& Coleman, 1963; Shapiro \& Bell, 1970a). Thus, while the term "subjective organization" has traditionally connoted subject-generated organizational units, perhaps the connotation of "subjective" as being more or less idiosyncratic is also appropriate.

\section{REFERENCES}

ABRAMCZYK, R. R., \& BOUSFIELD, W. A. Sequential ordering in repeated free recall as a function of interitem associative strength. Psychological Record, 1967, 17, 183-192.

ABRAMCZYK, R. R., \& BOUSFIELD, W. A. Multitrial free recall and sequential ordering of items having high variance of meaningfulness. Psychological Reports, 1969, 24, 343-350.

ANDERSON, R. C., \& WATTS, G. H. Bidirectional associations in multitrial free recall. Psychonomic Science, 1969, 15, 288-289.

BOUSFIELD, A. K., \& BOUSFIELD, W. A. Measurement of clustering and of sequential constancies in repeated free recall. Psychological Reports, 1966, 19, 935-942.

BOUSFIELD, W. A., \& ABRAMCZYK, R. R. Sequential ordering in repeated free recall as a function of the length of the stimulus word list. Canadian Journal Of Psychology, 1966, 20, 427-434.

BOUSFIELD, W. A., PUFF, C. R., \& COWAN, T. $M$. The development of constancies in sequential organization during repeated free recall. Journal of Verbal Learning \& Verbal Behavior, 1964, 3, 489-495.

CARTERETTE, E. C., \& COLEMAN, E. A. Some comments on Tulving's subjective organization. Technical Report No. 17, 1963, University of California, Los Angeles, Contract Nonr 233(58), Office of Naval Research.

GORFEIN, D. S., BLAIR, C., \& O'NEILL, C. R. A reanalysis of "The generality of free recall: I. Subjective organization as an ability factor." Psychonomic Science, 1969, 17, 110.

GORFEIN, D. S., BLAIR, C., \& ROWLAND, C. The generality of free-recall: I. Subjective organization as an ability factor. Psychonomic Science, 1968, 11, 279-280.

QUAINTANCE, B., \& SHAPIRO, S. I. The influence of class membership, method of presentation, and restricted association strength of free recall learning. Canadian Journal of Psychology, 1970, 24, 70-76.

SHAPIRO, S. I. Serial recall and prior free recall. Canadian Journal of Psychology, 1970, 24, 57-63.

SHAPIRO, S. I., \& BELL, J. A. Subjective organization and free recall: Performance of high, moderate, and low organizers. Psychonomic Science, in press.

SHAPIRO, S. I., \& BELL, J. A. Presentation order and the formation of subjective organization units in free recall. Paper presented at the meeting of the Midwestern Psychological Association, Cincinnati, April-May $1970 \mathrm{~b}$.

SHAPIRO, S. I., \& PALERMO, D. S. Mediated clustering in free recall. Journal of Experimental Psychology, 1967, 75, 365-371.

SHAPIRO, S. I., \& PONCE, I. Free recall and organization as functions of paced or unpaced responding and presentation rate. Psychonomic Science, 1970, 18, 329-330. 
THORNDIKE, E. L., \& LORGE, I. The teacher's word book of 30,000 words. New York: Bureau of Publications, Teachers College, Columbia University, 1944.

TULVING, E. Subjective organization in free recall of "unrelated" words. Psychological Review, 1962, 69, 344-354.

TULVING, E. Theoretical issues in free recall. In T. R. Dixon and D. L. Horton (Eds.), Verbal behavior and general behavior theory. Englewood Cliffs, N.J: Prentice-Hall, 1968. Pp. 2-36.

\section{NOTES}

1. The computation of bidirectional organizational units, i.e., disregarding the order in which the members of an organizational unit occur is a modification of Bousfield \& Bousfield's (1966) measure introduced by Gorfein, Blair, \& Rowland (1968).

2. The formula as originally presented was:

$$
\frac{\text { Observed }}{2(C-1)}-\frac{C}{h k}
$$

However, Arjan K. Jhangiani has pointed out that the derivation of this formula should lead to the present formulation, i.e.,

$$
\frac{\text { Observed }}{\mathrm{C}-1}-\frac{2 \mathrm{C}}{\mathrm{hk}} \text {. }
$$

\section{Increase in incentive amount with verbal reinforcement*}

\section{LAWRENCE WEINSTEIN, $\nmid$ University of Melbourne, Melbourne, Australia and \\ VINCENT M. COLUCCI, University of Maine, Portland, Maine 04103}

An increase in the amount of verbal reinforcement resulted in gradual, as opposed to sudden, increases in behavior and no evidence of positive incentive contrast effects. These results with human Ss agree with the data obtained from animal Ss and suggest that a shift in incentive size in humans affects learning as opposed to some more temporary mechanism.

Although reward decrements often produce negative incentive contrast effects in which the performance of the shifted Ss drops significantly below the level of the low-reward control group (e.g., Crespi, 1942; Weinstein, 1970), reward increments usually do not produce positive incentive contrast effects in which the performance of the shifted group rises significantly above the level of the high-reward control group (e.g., Ashida \& Birch, 1964; Collier, Knarr, \& Marx, 1961). While most studies have investigated the effects of shifting incentive magnitude with infrahuman organisms, few experiments have used human Ss. The present study attempted to determine how human $S$ s respond to an increase in incentive size.

Initially, in a pilot study it was determined that telling an $S$ immediately after his first answer to mental multiplication problems that he had received 7 points, 3 points, or 1 point results in high, intermediate, and low levels of performance, respectively. In the present study larger and smaller rewards are defined in terms of whether they

*We thank Paul Lee for running Ss.

$\dagger$ Requests for reprints should be sent to Lawrence Weinstein, Department of Psychology, University of Melbourne, Parkville, Victoria 3052, Australia. produce higher or lower levels of performance, respectively. SUBJECTS

The Ss were 13 male and 11 female undergraduate students enrolled in an introductory psychology course at the University of Maine at Portland. The Ss were assigned randomly to each of four equal groups.

\section{MATERIALS}

The materials consisted of a Kodak Carousel 750 -slide projector, $51 / 2 \mathrm{ft}$ from a $5 \frac{1}{2}$-in.-square piece of gray metal that served as a screen, $2 \times 1 \frac{1}{2}$ in. slides with digits typed on them (i.e., $776 \times 7$ ), and a stopwatch.

\section{PROCEDURE}

Each $\mathrm{S}$ worked a different sequence of the same 15 mental multiplication problems. One answer or $30 \mathrm{sec}$ (whichever came first )was allowed for each problem and there were $8 \mathrm{sec}$ between problems.

Table 1 summarizes the experimental procedure.

The problems were worked in four situations. Some Ss received no reinforcement after their answers (N). Other Ss received a high $(\mathrm{H})$ reward, 7 points, after answering the $1 \mathrm{st}$, 2nd, 4th, 6 th, 9th, 10th, 11th, 12th, and 14th problems, and, finally, some individuals received a low (LS) reward, 1 point, or a medium (MS) reward, 3 points, through Problem 11 and then experienced a shift in reinforcement magnitude to $\mathrm{H}$ after the 11 th problem.

Ss who received LS, MS, or $\mathrm{H}$ were read the following instructions: "This is an experiment in abstract problem solving, the ability to rapidly work problems involving abstract reasoning. You will be given some problems to work. Each one consists of a three-digit number multiplied by a one-digit number. You are to mentally, without pencil and paper, multiply the numbers as quickly as you can and then tell me your answer. You will receive from 1 to 10 points after each answer; the speed and accuracy with which you answer will earn you more points. You will be told periodically how you are doing." In the instructions to the $\mathrm{N}$ Ss, reference to receiving points was omitted. RESULTS

Latency means (the time between slide onset and the first response) were examined in the analysis of the results.

From Fig. 1 it appears that for Problems 1-11 the H Ss took less time to answer than did the LS or MS Ss, the MS individuals took less time to answer than the LS Ss, and, finally, the $\mathrm{N}$ group took longer to answer than the LS group.

The mean latency per problem from Problems 1-11 differed significantly among the four groups by analysis of variance $[F(3,20)=3.19, p<.05]$

By Mann-Whitney U tests the difference between $\mathrm{H}$ and LS, $\mathrm{H}$ and MS, LS and MS, and $\mathrm{LS}$ and $\mathrm{N}$ was each statistically significant $(p<.05)$.

Figure 1 indicates that for Problems 12-15, the MS and LS groups each took longer to answer than the $\mathrm{H} \mathrm{Ss}$. By Mann-Whitney $U$ tests, the mean latency per problem from Problems 12-15 differed significantly $(\mathrm{p}<.05)$ between $\mathrm{H}$ and $L S$, and $H$ and $M S$.

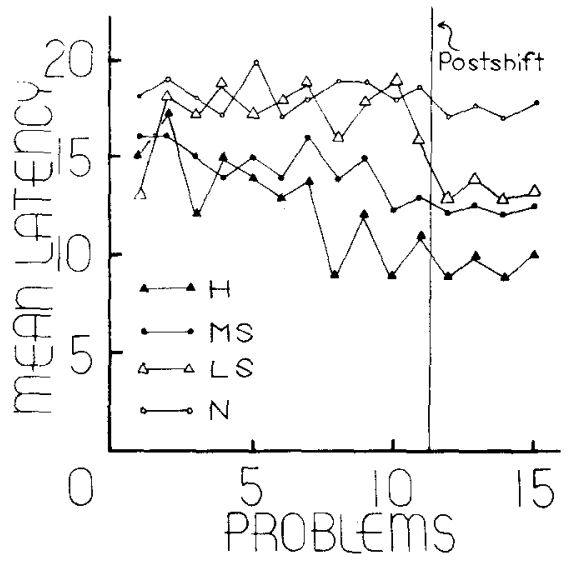

Fig. 1. Mean latency in seconds per problem. Groups LS and MS shifted after Problem 11 denoted by arrow. 